\title{
PATIENT AND PUBLIC INVOLVEMENT: FROM RHETORIC TO REALITY
}

\author{
Judith Deft, Manager, Morecambe Bay Patient Advice and Liaison Service \\ Westmorland General Hospital
}

\section{INTRODUCTION}

As of January $2003^{(1)}$, for the first time, every NHS organisation has had a mandatory duty to consult and involve patients and the public in the ongoing planning and delivery of services. This marks something of a sea change in the story of patient and public involvement within the health service. Previously, our statutory requirement was confined to formal consultation on 'substantial' service reconfigurations. Now, where any changes are anticipated, patients and the public must be demonstrably involved in developing proposals, not simply commenting on them. A couple of years ago, the Commission for Health Improvement (CHI) coined the phrase 'nothing about us without us' to describe the way it intended to work with patients and the public in the future $^{(2)}$. Undoubtedly, its replacement, the new Healthcare Commission (from 2004), will look for other NHS organisations to adopt similar principles.

As a starting point for this article, I have taken a recent report by $\mathrm{CHI}^{(3)}$ that summarises its findings from over three hundred $\mathrm{CHI}$ inspections over the last three years on the state of patient and public involvement (PPI) in the NHS. That report indicates that whilst PPI activity is on the increase, it is neither:

\section{- part of everyday practice, nor}

- having a major impact on policy and practice.

In other words, whilst CHI found pockets of individual good practice within NHS organisations, PPI is not central to those organisations' core activities. Further, they argue that there was little evidence of PPI directly leading to improvement, despite the plethora of recent initiatives. Perhaps it is the very number of centrally-generated initiatives that is part of the problem. Another $\mathrm{CHI}$ publication $^{(4)}$ lists 36 instances of new legislation, new structures and new mechanisms with a PPI focus, and we are still counting. Some are obvious; for example, the establishment of Patient and Public Involvement Forums, the commissioning of local Independent Complaints and Advocacy Services - more about both of these later. Others, some of those reading this article may not have immediately labelled as PPI, for example, Caldicott (handling confidential personal information), voluntary sector compacts (providing local frameworks for partnership working), consent to treatment and copying letters to patients.

Overall, CHI's report card could be summarised as 'trying hard, but could do better'. The NHS is getting better at some aspects of PPI, notably providing information and canvassing patients' opinions, we still have some way to go in involving patients, carers, service users and the wider public as equal partners in health service planning.
After a look at the new structures and frameworks that have been put in place to support PPI, I want to relate the $\mathrm{CHI}$ report to our own local experience within the Morecambe Bay health community in terms of the recent past, current position and future aspirations. It is by no means all bad news. Having joined the mainstream NHS as PALS manager from a Community Health Council (CHC - the former local health services 'watchdog') almost exactly two years ago, I have been impressed by the willingness of many working within the bay to engage in the PPI agenda whether in their individual capacity, for example modern matrons; as part of service teams, for example in hospital outpatients, learning disabilities and mental health or in a corporate support capacity, most notably the workforce development team featured elsewhere in this issue.

\section{PATIENT AND PUBLIC INVOLVEMENT STRUCTURES}

Undoubtedly there has been some confusion as to who does what since the final abolition of CHCs in December last year, so I make no apologies for this recap.

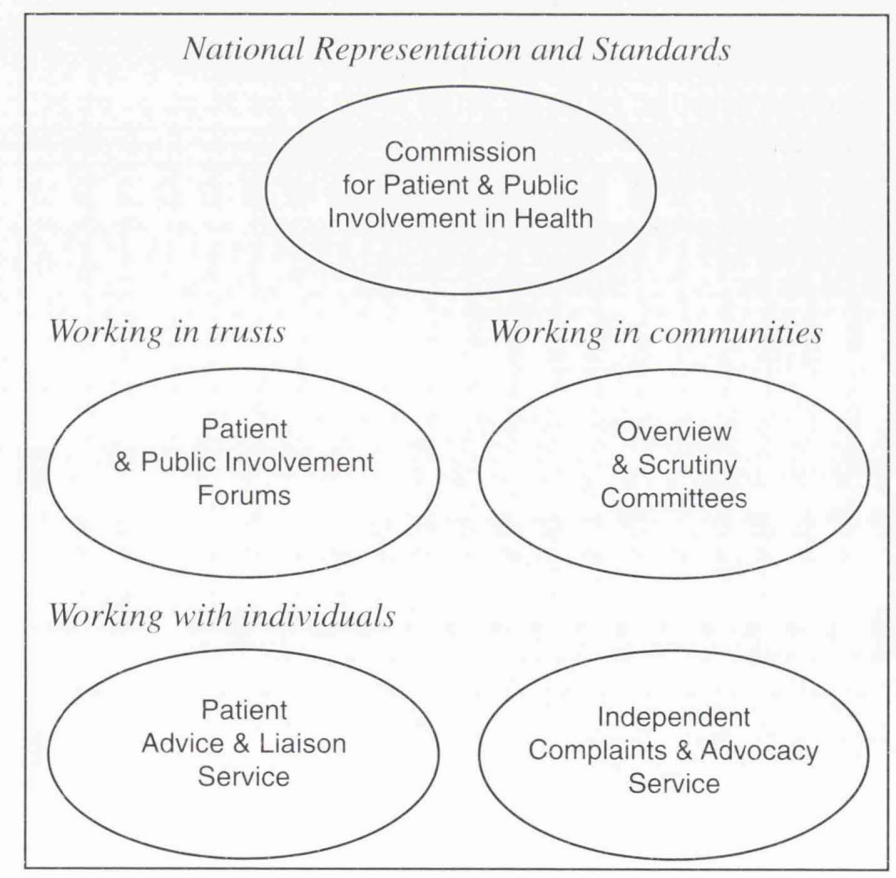

Figure I Patient and public involvement in the NHS

Figure 1 sets out a in diagrammatic form the PPI structures in place at three 'levels' - national, local and individual. A brief description of each of these components follows.

The Commission for Patient and Public Involvement in Health (CPPIH) is an independent, public body funded by the 
Department of Health (DoH). Responsible for setting national standards for the local Patient and Public involvement Forums and undertaking national reviews of services from the patient perspective, CPPIH reports to such as the Healthcare Commission and others on patient welfare and the DoH on PPI systems.

Patient and Public Involvement Forums (PPIFs) have been set up in each primary care trust/NHS trust in England (over 570 in total), to monitor and review day-to-day service delivery and, in the case of PCT forums, individual trusts' PPI arrangements. The forums have legal powers to inspect all premises where NHS services are provided and the intention is that each forum will elect a member to sit on their respective trust boards. In Morecambe Bay our two local forums are supported through the local voluntary service bureaux operating out of Kendal and Barrow.

Overview and Scrutiny Committees (OSCs) established by second-tier local authorities must be consulted on any substantial service changes within the NHS and retain a right of referral to an independent reconfiguration panel in cases of dispute. Morecambe Bay is covered by two OSCs (Cumbria and Lancashire) although there are provisions for the two to work together to respond to issues covering both areas.

The final two organisations support individuals.

Patient Advice and Liaison Services (PALS), now in 98\% of all trusts, give advice and information, work with staff to address individual concerns, pass on suggestions for service improvement and signpost individuals to PPI opportunities within their trust. Morecambe Bay has a joint PCT/hospitals trust service.

Independent Complaints and Advocacy Services (ICAS) provide independent support for individuals going through the formal NHS complaints system. ICAS for Morecambe Bay and North Cumbria is provided out of the Citizen's Advice Bureau based in Kendal.

Still very much in their infancy, these 'sons and daughters' of CHCs need to time to mature before their contribution to PPI can be fully evaluated.

\section{PATIENT AND PUBLIC INVOLVEMENT FRAMEWORK}

This issue of the Morecambe Bay Medical Journal is devoted to the 'patient experience'. In its reviews, CHI attempts to measure that experience under the following four headings:

- Getting the best treatment (clinical quality)

- Being treated as a person (humanity)

- Being safe and comfortable (environment)

- Being informed and given a choice.

By drawing in patients, carers and the wider public, PPI is about not only improving that experience but also improving the quality of decision-making between both individuals and professionals and between organisations and communities.

Some old hands at PPI will recognise the concept of the 'ladder of participation' ${ }^{(5)}$ that originated in the 1960 's. This is a pictorial representation that moves from a bottom rung where professionals are seen informing the public along the lines of "here's what we are going to do" through consulting, deciding together, acting together to a top rung where professionals are seen supporting local initiatives determined

\begin{tabular}{|c|c|c|c|}
\hline & Information & Feedback & Influence \\
\hline Individual & $\begin{array}{l}\text { Access to patient correspondence } \\
\text { Patient held records } \\
\text { Patient information } \\
\text { - Internet } \\
\text { - Leaflets } \\
\text { - Service prospectuses } \\
\text { - Verbal information }\end{array}$ & $\begin{array}{l}\text { Systems for collecting \& acting on } \\
\text { individual concerns, suggestions, } \\
\text { complaints } \\
\text { - Comment cards } \\
\text { - Formal complaints } \\
\text { - Patient Advice \& Liaison } \\
\quad \text { Service (PALS) }\end{array}$ & $\begin{array}{l}\text { Advocacy } \\
\text { Care programme approach } \\
\text { Customer care practice } \\
\text { Expert patient } \\
\text { Informed consent } \\
\text { Integrated care pathways }\end{array}$ \\
\hline Collective & $\begin{array}{l}\text { Annual plans \& reports } \\
\text { - Business } \\
\text { - Clinical governance } \\
\text { - Public involvement } \\
\text { - Service } \\
\text { - Statutory } \\
\text { Communications strategy } \\
\text { - Internal } \\
\text { - Patient prospectus } \\
\text { - Press \& media } \\
\text { - Voluntary sector } \\
\text { Performance information }\end{array}$ & $\begin{array}{l}\text { Complaints/PALS monitoring } \\
\text { Patient/ carer experience methods } \\
\text { - Focus groups } \\
\text { - Interviews } \\
\text { - Patient diaries } \\
\text { - Shadowing } \\
\text { - Surveys } \\
\text { Patient panels/user-carer forums }\end{array}$ & $\begin{array}{l}\text { Citizens juries } \\
\text { Consultation } \\
\text { - Formal } \\
\text { - Informal } \\
\text { Lay representation } \\
\text { Local healthy alliances } \\
\text { - Neighbourhood } \\
\text { - regeneration } \\
\text { - Sure Start } \\
\text { - Healthy Living Centres } \\
\text { Overview \& Scrutiny } \\
\text { Partnership boards } \\
\text { - Multi-agency } \\
\text { - Service specific } \\
\text { Patients forums } \\
\text { Priority setting } \\
\text { Stakeholder conferences } \\
\text { Training \& recruitment }\end{array}$ \\
\hline
\end{tabular}

Figure 2 Source: Morecambe Bay Health Community Joint Patient \& Public Involvement Strategy 2003-06 (July 2003) 
by the public, "we can help you achieve what you want within these guidelines".

Personally, I find the ladder a little problematic in so far as it implies that the further up you are the 'better', intrinsically, your PPI. In reality, you are much more likely to be continuously moving up and down that ladder as appropriate for each situation. More useful, as a framework for planning and evaluating an organisation's PPI - and one we have used in Morecambe Bay - is the notion of a grid (see Figure 2) ${ }^{(6)}$.

On the left hand side of the grid sit:

- Individuals (involvement in their own care)

- Collective (involvement in service delivery, policy and planning).

Whilst along the top, run:

- Information (about treatments, services, the organisation)

- Feedback (complaints, patient experience)

- Influence (shared decision-making, involvement in policy and planning).

Figure 2 uses the grid to make sense of some of those 36 PPI initiatives referred to earlier; the grid works equally well for individual directorates and services wanting to assess their own PPI activities - past, current or planned.

\section{COULD DO BETTER ...}

So what are the $\mathrm{CHI}$ reviews telling us about the state of PPI nationally? PPI is one of the seven components of clinical governance scored on a scale of (i) - the lowest to (iv) - the highest. Figure 3 shows the percentage of trusts reviewed up to December 2003 scoring either a (iii) or (iv) for each of the seven components. Not only does PPI have the lowest percentage ( $8 \%$ ) but in fact no trust has scored a (iv) to date.

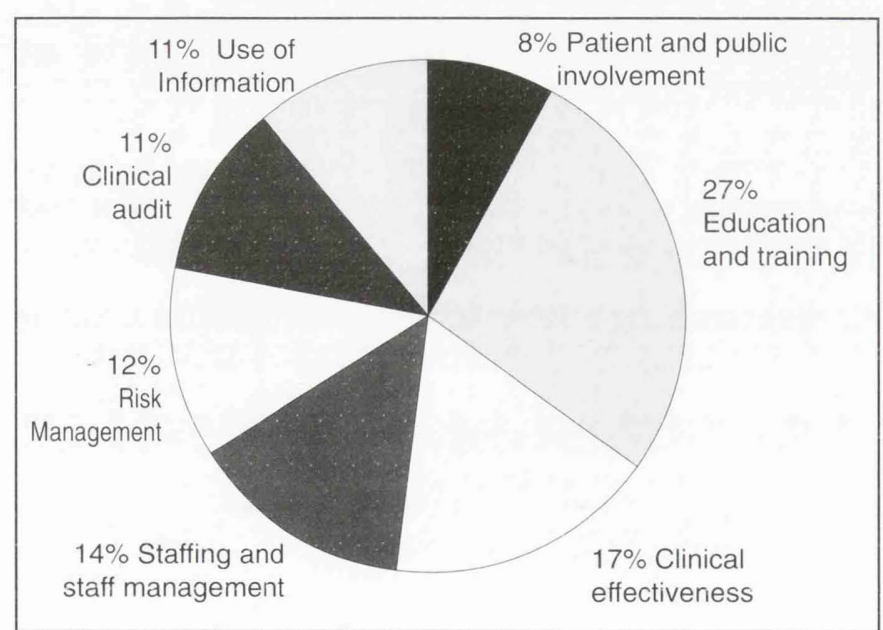

Figure 3 Source: Commission for Health Improvement (2004): Sharing the Learning on Patient \& Public Involvement from CHI's work i2i Involvement to Improvement Gilbert D, King J

Looking locally, CHI reviewed the hospitals trust back in 2001, when PPI within the trust rated a (ii) noting that there had been "worthwhile progress and development at operational level but not at the strategic and planning levels". Ad hoc examples of good practice were cited in maternity, paediatrics and breast care services. Two years later the primary care trust was reviewed by which time the (ii) rating had been expanded to include categories a) to c). Morecambe Bay PCT was rated as a (ii)c that is, "worthwhile progress and development at strategic, planning and operational level but not across the whole organisation". Progress had clearly been made in that intervening period but the fact remains that PPI is largely as a result of individual enthusiasm and drive rather than as an integral part of the organisations' activities. Judging from the national CHI ratings, Morecambe Bay is clearly not alone in that

The recent $\mathrm{CHI}$ study went on to list the challenges organisations face in responding to the PPI agenda. These fell under the following key headings:

- Strategies and plans

- Organisational commitment

- Mainstreaming

- Feedback to influence

- Roles and responsibilities

- Influencing change, supporting staff

- Working together.

For the remainder of this article, I want to respond to CHI's findings with some personal observations based on the last two years, during which time I have been increasingly drawn into PPI activities. Although required to produce longterm PPI strategies, $\mathrm{CHI}$ commented that many organisations were attempting to run before they could walk and needed to link PPI more closely to existing groups and operational priorities.

Morecambe Health Community's PPI strategy, covering the period 2003-2006, was approved by both trust boards last summer and an implementation plan for the first six months agreed at the end of September. I was closely involved in both and I make no apologies for the breadth and ambition of the overall strategy whose purpose is, after all, to set a direction of the travel for the next three years. However, it has been difficult to meet the timescales set in that first implementation plan; these have been substantially revised following the PCT's CHI review. An implementation group has now been set up which will seek to make progress in four key areas:

- A baseline assessment of current and planned PPI activities that will identify best practice, gaps and ways of working that suit different directorates, services and improvement teams. This assessment will include corporate as well as clinical services.

- Identifying individuals within both organisations with an interest in PPI who can act as champions within their own services and provide a link between those services and the central group. It is intended that these individuals would be able to access training on PPI approaches and techniques in order to develop local capacity to undertake PPI.

- Identifying a budget for PPI work. In the current financial climate, we would be looking for a small amount of money to 'pump prime' PPI activity within individual directorates and services and to support the capacity building referred to above. 
- A Morecambe Bay-wide policy for the payment of service users, carers and the public involved in PPI activities. To date, individual services have made ad hoc arrangements. It is obviously important that we recognise the contribution lay people will make in future but equally services need to know they are working on a level playing field.

The CHI study went on to talk about PPI being built into business cases and policy formulation from the start, and the importance of mainstreaming PPI from ensuring individual staff having built-in responsibilities for PPI through to patients/service user representatives sitting close to corporate decision-making bodies.

Taking the last point first, in Morecambe Bay, we have a prime example in the Local Partnership Boards within Learning Disability Services, where service users themselves sit on (not just close to) those bodies. It takes time (and support for both sides) to get to this point. In the NHS time is often against us. For example, those responsible for CHOICE and the Morecambe Bay Contact Centre initiatives have been looking at how they can ensure meaningful PPI in those projects yet still meet nationally-set deadlines. The solution is by no means perfect but at least it is workable.

Generally, the word 'representative' always causes problems. A year or so ago, we took a snapshot of which PPI methods were most commonly being used in Morecambe Bay. Inviting a patient/user representative to sit on a group or committee proved the most popular. Yet time and time again, NHS professionals bemoan the fact that the patient/service user is not representative. Very simplistically, I believe a representative should have some sort of formal constituency for example, a voluntary organisation, a Patient and Public Involvement Forum, a local authority, that in turn gives that representative a mandate. Equally valuable is someone able to give a patient/service user perspective. It may be that we have to seek several perspectives because it is unrealistic to expect a single patient/service user without a constituency to be 'representative'. The trick is knowing which is needed when.

The CHI study refers to certain PPI initiatives as being confined to 'safe' areas (patient information, ward environment) as if, in some way, they were less important because those initiatives were more about feedback than influence. If my experience with PALS has taught me anything it is that little things matter to patients and service users. Elsewhere in this issue of the journal the use of patient videos has been mentioned. In one such video, an older person described how she felt unable to eat the large sandwich put in front of her. This video was seen by nursing auxiliaries in the hospitals trust. A couple of weeks later they reported back that on their wards, sandwiches were now being cut into quarters. It sounds so minor but not only will it make a difference to the next patient, it also demonstrates that good PPI does not have to be difficult, resource-intensive or costly. A recent article in the Health Service Journal ${ }^{(7)}$ reporting on research by Mori suggests that there is no relationship between either mortality ratios and patient perception of hospital care or between star ratings and public perceptions of performance but there was a very strong correlation between the extent to which patients feel they are treated with dignity and respect and their overall perception of the hospital.

\section{... BUT WILL TRY HARDER}

CHI's study concludes that these are exciting, if slightly confusing, times for PPI. In Morecambe Bay it certainly feels like that. The central plank of the joint PPI strategy is to build effective and continuous PPI at all levels into the daily work of the local health community. This will not be a quick fix but we believe the direction of travel is the right one. In order for PPI to be successful there needs to be a commonly shared understanding that it cannot always be scientifically based, is not just about formal methods and structures (although these have to be robust) and is rarely perfect.

Finally, it would be remiss of me not to refer to Foundation Trusts. The prospect of up to 10,000 accessible individuals with a declared interest in the way that local health services are developed sounds a PPI manager's dream ticket. Whatever the outcome of the current process, there has been real value in identifying the ways and means that other organisations in Morecambe Bay - particularly in local government and the voluntary sector - engage with their users and members respectively. Not only are there valuable lessons we can learn from them, but we can, by working together, achieve a better end result. It is good to know we are not on our own.

\section{REFERENCES}

1 Health \& Social Care Act 2001: Section 11; Department of Health (2003): Strengthening Accountability - Involving Patients \& the Public - Policy Guidance \& Practice Guidance

2 Commission for Health Improvement (2002): A Patient and Public Strategy for CHI

3 Commission for Health Improvement (2004): Sharing the Learning on Patient \& Public Involvement from CHI's work i2i Involvement to Improvement Gilbert D, King J

4 Commission for Health Improvement (2003) An A-Z of Current Patient \& Public Involvement Issues \& Guidance

\section{Wilcox (1966) Guidelines to Effective Participation}

6 NHS Cymru/National Assembly for Wales Signposts (2001) A practical guide to public \& patient involvement in Wales

7 Page B. What they really really want HSJ 2004; 114(5900):16-19 